\title{
ENFERMAGEM BASEADA EM EVIDÊNCIAS: PRINCÍPIOS
}

E APLICABILIDADES

Edvane Birelo Lopes De Domenico ${ }^{1}$

Cilene Aparecida Costardi Ide ${ }^{2}$

Domenico EBLD, Ide CAC. Enfermagem baseada em evidências: princípios e aplicabilidades. Rev Latino-am Enfermagem 2003 janeiro-fevereiro; 11(1):115-8.

O trabalho discorre sobre a enfermagem baseada em evidências, como um novo modelo operacional integralizador da competência clínica individual, com os achados clínicos gerados pelas pesquisas científicas, e analisa a inserção dessa prática no modelo profissional vigente na enfermagem.

DESCRITORES: enfermagem prática, pesquisa em enfermagem, papel do profissional de enfermagem

\section{EVIDENCE BASED NURSING: PRINCIPLES AND APPLICABILITY}

The work considers the evidence based nursing as a new operational model that integrates individual clinical competencies, through clinical finding generated by scientific research and analyzes the inclusion of this practice to the actual nursing professional model.

DESCRIPTORS: nursing practice, nursing research, nursing professional role

\section{ENFERMERÍA BASAdA EN EVIDENCIA: PRINCÍPIOS Y APLICABILIDAd}

El presente trabajo trae la práctica basada en evidencias como un nuevo modelo operacional integralizador de la competencia clínica individual con los avances clínicos generadas por las investigaciones científicas y analiza la inclusión de esta practica en el modelo profesional vigente en enfermería.

DESCRIPTORES: enfermería práctica, investigación en enfermería, rol del profesional de enfermeria

\footnotetext{
${ }^{1}$ Doutoranda, Mestre em Enfermagem pela Escola de Enfermagem da Universidade de São Paulo, Docente do Curso de Graduação em Enfermagem da Universidade Paulista, e-mail: erdomenico@sti.com.br; ${ }^{2}$ Professor Titular da Escola de Enfermagem da Universidade de São Paulo
} 


\section{INTRODUÇÃO}

O conhecimento está em pleno estado de desenvolvimento e aprimoramento na sociedade moderna, e isso implica a possibilidade de encontrarmos, na prática, atitudes desvinculadas dos últimos achados científicos. Nas profissões da área da saúde, o acompanhamento atualizado dos resultados de pesquisas já se tornou uma prática impossível quando o profissional não prioriza uma determinada especialidade e, mesmo assim, a tarefa continua sendo difícil, uma vez que deverá planejar seu tempo para, periodicamente, proceder à seleção, leitura e análise dos estudos publicados na área de escolha.

Nesse contexto de urgente adoção de medidas que minimizem o distanciamento entre os avanços científicos e a prática assistencial, surgiu, inicialmente, no campo da Medicina, e, posteriormente, na Enfermagem, a Prática Baseada em Evidências (PBE).

Sendo uma proposta nova no contexto assistencial dos enfermeiros, o presente trabalho é um ensaio sobre o assunto, com os objetivos de elucidar seus princípios e analisar sua aplicabilidade na Enfermagem.

\section{PRINCÍPIOS DE UMA PRÁTICA BASEADA EM EVIDÊNCIAS}

Por definição, a Prática Baseada em Evidências (PBE) compreende "o uso consciente, explicito e judicioso da melhor evidência atual para a tomada de decisão sobre o cuidar individual do paciente" ${ }^{\prime(1)}$. Compreende um processo integralizador da competência clínica individual com os achados clínicos gerados pelas pesquisas sistemáticas existentes e nos princípios da epidemiologia clínica ${ }^{(1-2)}$.

Os elementos da Prática Baseada em Evidências são constituídos pelas técnicas de tomada de decisão clínica, pelo acesso às informações científicas e pela análise da validade dessas informações, principalmente averiguando os graus de eficiência e efetividade que possuem ${ }^{(3)}$.

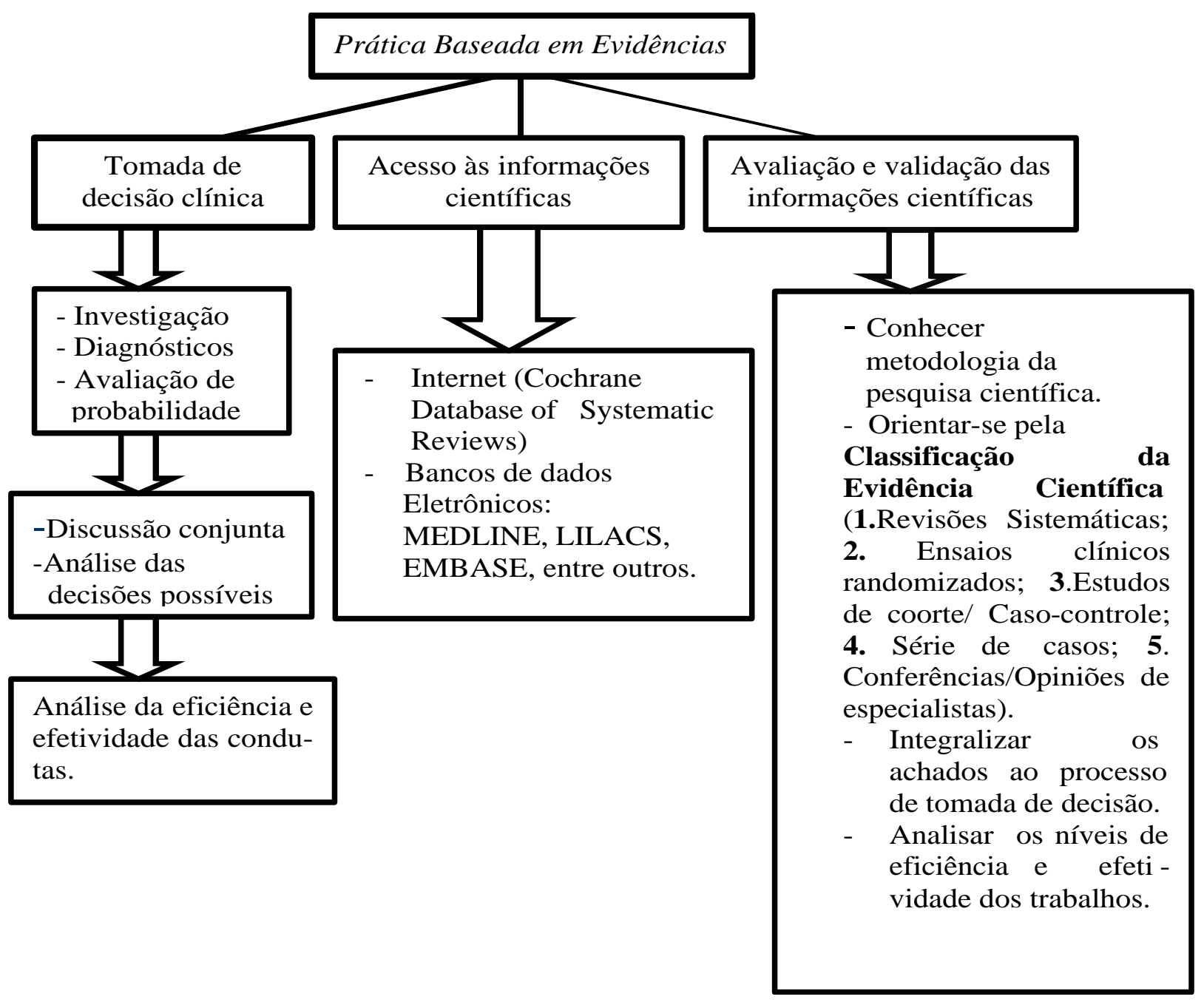

Figura 1 - Elementos constituintes da prática baseada em evidências 
Analisando-se a Figura 1, verifica-se que, em outras palavras, os elementos básicos da PBE consistem no exercício da avaliação clínica e no processo de integração e aplicação das evidências externas àquela realidade observada.

Operacionalmente, a PBE baseia-se em cinco etapas que integram esses elementos ${ }^{(1,3-5)}$. Primeiramente, a necessidade de cuidado observada no paciente, num grupo de pacientes ou mesmo na organização do serviço, deve ser convertida numa pergunta; a segunda etapa consiste na busca bibliográfica da melhor evidência relacionada à pergunta. A seguir, as evidências encontradas são avaliadas em termos de validade e confiabilidade metodológica, além da sua aplicabilidade clínica.

Nessa etapa, os conhecimentos sobre metodologia da pesquisa são importantes para o profissional analisar, com segurança, o desenho da pesquisa, a exposição de sua condução, e os métodos estatísticos empregados. Como fonte de auxílio para a realização dessa análise, o Centro Cochrane do Brasil (http://www.epm.br/cochrane) disponibiliza as Revisões Sistemáticas já realizadas, como também auxilia na busca de ensaios clínicos registrados. As Revisões Sistemáticas construídas com a meta-análise são consideradas as melhores evidências sobre determinados assuntos, uma vez que a associação da revisão meticulosa da literatura ao método estatístico possibilita a aquisição de resultados combinados e avaliados qualitativamente (revisão da literatura) e quantitativamente (meta-análise), podendo-se inferir a magnitude do efeito da intervenção, as diferenças e contradições entre diferentes estudos, o grau de confiabilidade, entre outras análises que não sofrem a influência da posição do autor ${ }^{(1,3)}$.

A quarta etapa operacional da PBE compreende a aplicação, na prática clínica, dos achados escolhidos mediante a análise crítica da literatura investigada. E, finalmente, a quinta etapa consiste na avaliação dos resultados.

Para a operacionalização dessas etapas, o profissional necessita construir competências relacionadas, principalmente: 1 . À capacidade de analisar criticamente o contexto da prática; 2 . À habilidade de converter situações-problema em foco investigativo; 3 . Ao conhecimento sobre metodologia de pesquisa: desenho do estudo, análises de confiabilidade, efetividade, custobenefício; 4. À capacidade de associar os achados científicos ao seu contexto de prática; 5. À habilidade de implementar mudanças e de avaliá-las continuamente ${ }^{(5-6)}$.

\section{APLICABILIDADE DA PBE NA ENFERMAGEM}

Expostos os referenciais que sustentam a Prática Baseada em Evidências, cabe colocá-la em destaque, considerando os limites e as perspectivas de sua aplicabilidade. Nesse contexto, a utilização dessa metodologia tem, como condição imediata de aplicabilidade, os movimentos de acreditação da prática instituída, cada vez mais alicerçados no pensamento crítico e na competência clínica dos enfermeiros, enquanto requisitos para a coordenação de processos de cuidar, sustentados pelas melhores evidências científicas.

Trilhar a trajetória de uma Prática Baseada em Evidências compreende redimensionar prioridades, reinvestir na avaliação clínica da clientela e disponibilizar tempo para empreendimentos relacionados à busca de resultados de pesquisa, ou mesmo à sua execução. A participação do paciente e a utilização da experiência profissional do enfermeiro também são essenciais, na medida que fornecerão subsídios para a determinação das necessidades (diagnósticos) e das condutas de cuidar, devidamente pautadas em melhores evidências científicas $^{(6)}$.

Enquanto profissão institucionalizada, a Enfermagem envolve-se e responde, também, por uma gestão administrativa caracterizada, essencialmente, pela pouca flexibilidade e racionalidade operacionais ${ }^{(4-5)}$. Para que os enfermeiros possam penetrar num contexto administrativo/assistencial resignificado, é necessário que ocorra, inclusive, uma análise crítica pessoal sobre a qualidade profissional que se possui e o que se faz para cultivá-la ${ }^{(6)}$.

Nesse sentido, a qualidade da formação universitária e as oportunidades científicas da vida profissional estão relacionadas, uma vez que 0 desenvolvimento das habilidades concernentes a um profissional que seja capaz de atuar com os parâmetros das melhores evidências, não se constrói repentinamente. Desde a graduação, o aluno deveria habituar-se a questionar e investigar o contexto da prática, porém, concomitantemente, torna-se fundamental uma nova estrutura administrativa do trabalho, baseada na disponibilidade de recursos e na reformulação filosófica da prática, realinhando as atividades profissionais para a investigação clínica permanente. 


\section{REFERÊNCIAS BIBLIOGRÁFICAS}

1. Atallah AN, Castro AA. Evidências para melhores decisões clínicas. São Paulo, Centro Cochrane do Brasil; 1998.

2. French $P$. The development of evidence-based nursing. $J$ Adv Nurs 1999; 29(1):72-8.

3. Friendland DJ, Go AS, Davoren JB, Shlipak MG, Bent, SW, Subak LL, et al. Medicina baseada em evidências: uma estrutura para a prática clínica. Rio de Janeiro: GuanabaraKoogan; 2001.

4. Colyer H. Evidence-based practice: philosophical and political anlysis: some matters for consideration by professional practitioners. J Adv Nurs 1999; 29(1):188-93.

5. Isern MTI. La evidencia cientifica: estrategia para la prática enfermera. Rev Rol Enfermeria 1999; 22(3):185-90.

6. Sastre RS, Solís MJN. Investigar desde la teoría y la prática. Rev Rol Enfermeria 2000; 23(3):185-91. 